\title{
SASKATCHEWAN CHRISTMAS MAMMAL COUNT, 1974
}

\author{
Compiled by WAYNE C. HARRIS
}

Mild weather and almost no snow er in some localities resulted in exlent results on counts this year. A al of 16 localities reported 15 cies of mammals, almost doubling year's coverage. The lack of snow er resulted in observation of eral species of small mammals not orded last year, including the adow Vole and Deer Mouse.

he most frequently recorded cies, the White-tailed Jackrabbit, rains common in most areas and the wshoe Hare populations appear to increasing again. Coyotes also ap$r$ to have shown an increase, being recorded on nine counts compared to two last year.

For weather, coverage and participants, please refer to Christmas Bird Counts elsewhere in this issue.

Symbols found in the table:

*Identified by tracks (number of animals by tracks in parentheses).

+ Seen during count period but not on count day.

'Box 93,

Raymore, Saskatchewan

SOA $3 J 0$

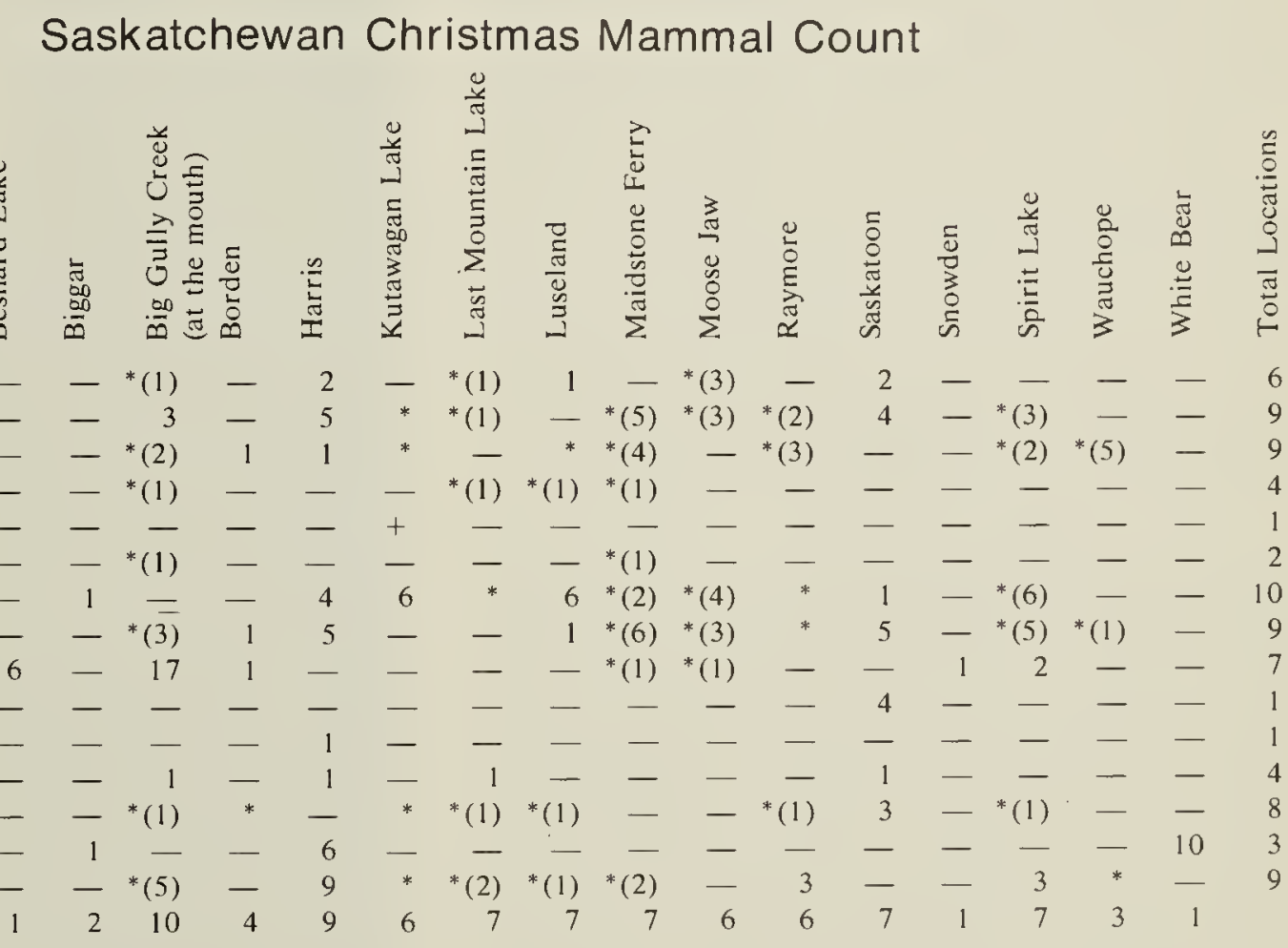

ndhill Crane Refuge, Nebraska - The Interior Department is moving ahead wly to acquire land from willing sellers (Gov. J. James Exon will withdraw his pport if Federal official's try to condemn key parcels).

From National Wildlife. 